\title{
Current and never smokers: differentials in characteristics, knowledge and perceptions
}

R.M. Youssef, ${ }^{1}$ S.A. Abou-Khatwa ${ }^{1}$ and H.M. Fouad ${ }^{1}$

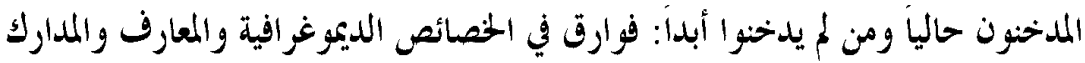

$$
\begin{aligned}
& \text { رندة يوسف، سامية أبو خطوة، هبة فئواد }
\end{aligned}
$$

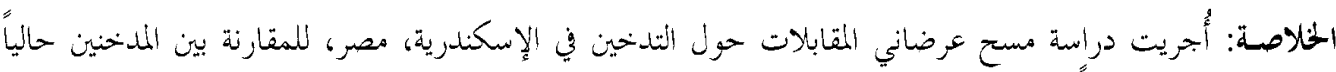

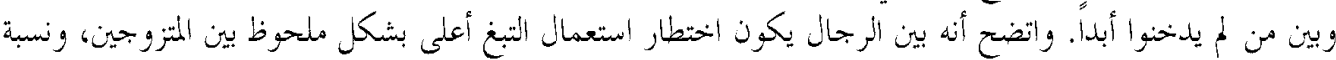

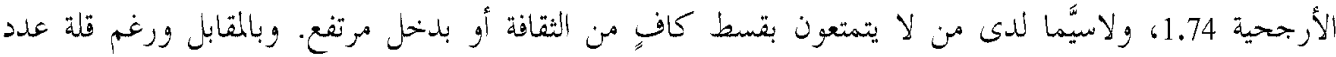

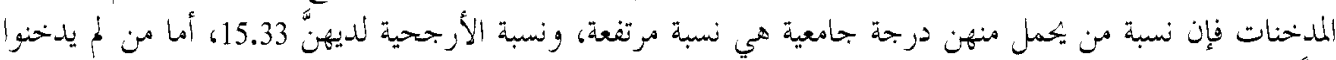

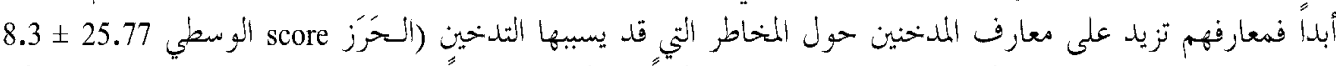

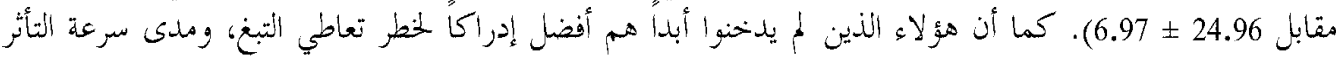

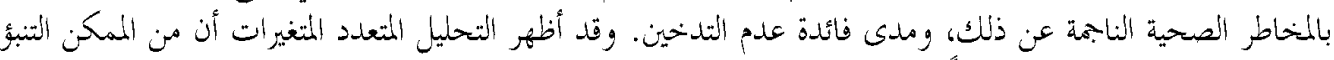

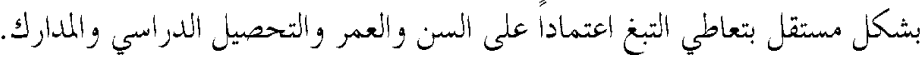

ABSTRACT A cross-sectional interview survey of tobacco use was conducted in Alexandria, Egypt, comparing current smokers with never smokers. Among men, the risk of current tobacco use was significantly higher among married participants $(O R=1.74)$, especially those with low educational or occupational status. In contrast, although few women smoked, tobacco use was significantly higher among those holding a university degree $(O R=15.33)$. Never smokers were significantly more knowledgeable than current smokers about tobacco-related health hazards. Never smokers had significantly better perceptions of the danger of tobacco use, susceptibility to health-related hazards and the benefits of being tobacco-free. Multivariate analysis revealed that tobacco use is independently predicted by participants' sex, age and educational attainment as well as their perceptions.

Fumeurs actuels et personnes n'ayant jamais fumé : différences dans les caractéristiques démographiques, les connaissances et les perceptions

RESUME Une enquête transversale par entretien sur la consommation de tabac a été réalisée à Alexandrie (Egypte), comparant les fumeurs actuels et les personnes n'ayant jamais fumé. Chez les hommes, le risque de consommation actuelle de tabac était significativement plus élevé chez les participants mariés $(O R=1,74)$, notamment chez ceux qui avaient un faible niveau d'instruction ou un statut professionnel peu élevé. Par contre, même si peu de femmes fumaient, la consommation de tabac était significativement plus élevée chez celles qui étaient titulaires d'un diplôme universitaire $(O R=15,33)$. Les personnes n'ayant jamais fumé connaissaient beaucoup mieux les risques pour la santé liés au tabagisme que les fumeurs actuels. Les personnes n'ayant jamais fumé avaient des perceptions significativement meilleures du danger de la consommation de tabac, de la sensibilité aux risques pour la santé liés au tabagisme et des avantages de ne pas fumer. L'analyse multivariée a révélé que la consommation de tabac est prédite indépendamment par le sexe et l'âge des participants, par leur niveau d'études ainsi que par leurs perceptions.

${ }^{1}$ Department of Community Medicine, Faculty of Medicine, University of Alexandria, Alexandria, Egypt Received: 25/08/02; accepted: 21/04/03

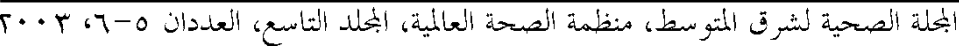




\section{Introduction}

In many industrialized countries, tobacco use and cigarette consumption have been declining [1]. However, data reported by the Eastern Mediterranean Region of the World Health Organization indicated that, in contrast to the other 5 regions, cigarette consumption was not declining in any of the member countries, and in fact the great majority of countries showed a trend towards increasing consumption [2].

An Egyptian survey conducted in 1977 revealed that $32.5 \%$ of men and $1.5 \%$ of women were tobacco users [3]. In a survey in Cairo in 1982, the prevalence among men had increased to $39.8 \%$ while that of women remained low at $1.0 \%$ [3]. In fact, Egyptians' demand for tobacco is strongly increasing as tobacco sales grow at a rate of $5 \%$ to $10 \%$ per year [4]. Simultaneously, the average annual per capita cigarette consumption by those aged 15 years and over rose from 730 in 1972 to 1210 in 1992 [2]. Expenditure on tobacco imports, which represent $1 \%$ of Egypt's total imports, is relatively large and poses a significant burden on the country's economic development $[2,5]$.

Public surveys illustrating patterns of tobacco use and laying emphasis on factors influencing smoking behaviour have been identified as areas of research priority for developing countries and an important component of the global health research agenda [6]. These tobacco surveys should be conducted at a minimum of 5-year intervals to illustrate trends over time [7]. Surveys that include broad sectors of the population as well as different age groups can identify populations at risk. Moreover, the assessment of public knowledge and perceptions in respect to tobacco use and its adverse consequences will help in the development of targeted health education programmes. For this purpose, a commu- nity-based survey was conducted in Alexandria, Egypt's second largest city and main port, with a population of 3339076 in 1996. A previous paper from this survey has reported on the prevalence and age of initiation of smoking among this population [8]. This paper compares current smokers with never smokers in respect to demographic characteristics, knowledge of tobacco-associated morbidity and perceptions of tobacco-related health risks, as well as the benefits of staying tobaccofree.

\section{Methods}

A community-based survey using cluster sampling was conducted in Alexandria city between May and August 2000, including 2120 subjects aged 15 years and over. Further details of the sampling methods are reported in an earlier paper [8].

\section{Questionnaire}

Data were collected using a pre-tested, precoded interview questionnaire. Section I recorded the participants' characteristics (age, sex, education, occupation, and marital status), chronic health problems (including hypertension, diabetes, bronchial asthma, ischaemic heart disease and rheumatic heart disease) and level of physical activity. Physical activity was classified into 'sedentary' for absence of any physical activity, 'light' for walking during usual activities, 'moderate' for brisk walking and 'vigorous' if the participant played a sport.

Section II used the WHO core questions for tobacco surveys [7] to classify the smoking status of participants as: current smokers, never smokers or ever smokers.

Section III assessed participants' knowledge of tobacco-associated morbidity using 14 questions based on a review of 
the literature. Participants were first requested to nominate problems without being prompted, and were then prompted to test their recall. Answers were scored as follows: problem mentioned without being prompted (score 2), problem recalled when prompted (1) and problem neither mentioned nor recalled (0). The total score ranged from $0-28$ with higher scores indicating better knowledge ( $\alpha$-reliability $=$ 0.91). Participants were asked to state their source of knowledge about tobacco-related conditions.

Section IV assessed participants' perceptions of tobacco-related risks with a total of 19 questions covering 3 areas of perceptions: danger, susceptibility and benefits. For each question, responses were scored as follows: strongly agree (score 2), somewhat agree (1) and don't agree (0). There were 7 questions about the hazards associated with tobacco use (range of scores 0-14); higher scores indicated a stronger perception of danger ( $\alpha$-reliability $=0.92$ ). Five questions were about the susceptibility of tobacco users to tobaccoassociated illnesses (range $0-10$ ); higher scores indicated stronger perception of susceptibility $(\alpha$-reliability $=0.90)$. Seven questions asked about the benefits associated with refraining from tobacco use (range 0-14); higher scores on this scale indicated stronger perception of benefits $(\alpha$-reliability $=0.93)$.

\section{Data analysis}

The data were analysed using SPSS, version 8.0 and Epi-Info, version 6.04. Data gathered from the cross-sectional survey were analysed using the case-control approach where current smokers represented the cases and never smokers the controls with the aim of identifying risk factors underlying continuing use of tobacco. The mean \pm standard deviation (s), odds ratio
(OR) and the corresponding 95\% confidence interval (CI) were computed. The chi-squared and the Student $t$-test were used to test the significance of the results. Tobacco use was modelled as a function of participants' characteristics as well as their knowledge and perceptions.

\section{Results}

The total sample was 1162 men and 958 women. Among the men, 48.5\% (95\% CI: 45.63-51.37) were current smokers compared with $1.5 \%$ (95\% CI: $0.74-2.26$ ) of women. Current smokers had maintained their habit for nearly 20 years (mean $21.1 \pm$ 1.3 years) with an average daily consumption of $23.2 \pm 12.5$ cigarettes.

Table 1 shows the demographic characteristics of current smokers compared with those who never smoked. In the surveyed community, men were 71 times more likely to be current tobacco users than were women. A significant linear association was observed between age and current tobacco use $(P<0.001)$. Relative to the youngest age group (15-24 years), the likelihood of current tobacco use increased steadily with increasing age and was nearly 3 times higher among those aged 35 years and older.

A statistically significant association between educational level and tobacco use was observed for both men $\left(\chi_{3}^{2}=47.87, P\right.$ $<0.001)$ and women $\left(\chi_{3}^{2}=18.50, P<\right.$ 0.001 ). Among men, a significantly higher percentage of current smokers were illiterate or just able to read and write (51.6\%) compared with never smokers (32.1\%) (Table 1). Relative to university graduates, those who were illiterate or just able to read and write were 2.62 times more likely to be tobacco users. The risk decreased among those who had accomplished basic (OR = 1.59) or high school education $(\mathrm{OR}=$

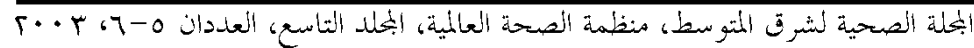


Table 1 Demographic characteristics of participants by smoking status

\begin{tabular}{|c|c|c|c|c|c|c|}
\hline \multirow{2}{*}{$\begin{array}{l}\text { Demographic } \\
\text { characteristics }\end{array}$} & \multicolumn{2}{|c|}{ Never smokers } & \multicolumn{2}{|c|}{ Current smokers } & \multirow[t]{2}{*}{ OR } & \multirow[t]{2}{*}{$95 \% \mathrm{Cl}$} \\
\hline & No. & $\%$ & No. & $\%$ & & \\
\hline Age (years) & \multicolumn{2}{|c|}{$(n=1469)$} & \multicolumn{2}{|c|}{$(n=577)$} & & \\
\hline $15-<25$ & 471 & 32.1 & 88 & 15.2 & 1.00 & \\
\hline $25-<35$ & 372 & 25.3 & 127 & 22.0 & 1.83 & $1.35-2.48$ \\
\hline $35-<5$ & 286 & 19.5 & 147 & 25.5 & 2.75 & $2.03-3.72$ \\
\hline $45-<55$ & 212 & 14.4 & 139 & 24.1 & 3.51 & $2.56-4.79$ \\
\hline \multirow[t]{2}{*}{$55+$} & 128 & 8.7 & 76 & 13.2 & 3.18 & $2.21-4.57$ \\
\hline & & & & & \multicolumn{2}{|c|}{$\chi^{2}=73.70, P<0.001$} \\
\hline Sex & \multicolumn{2}{|c|}{$(n=1469)$} & \multicolumn{2}{|c|}{$(n=577)$} & & \\
\hline Women & 940 & 64.0 & 14 & 2.4 & 1.00 & \\
\hline Men & 529 & 36.0 & 563 & 97.6 & 71.46 & $41.61-122.73$ \\
\hline \multicolumn{7}{|l|}{ Education } \\
\hline Men & \multicolumn{2}{|c|}{$(n=529)$} & \multicolumn{2}{|c|}{$(n=563)$} & & \\
\hline Illiterate/read and write & 170 & 32.1 & 291 & 51.6 & 2.62 & $1.83-3.75$ \\
\hline Primary/preparatory & 75 & 14.2 & 78 & 13.9 & 1.59 & $1.02-2.47$ \\
\hline Secondary & 180 & 34.0 & 126 & 22.4 & 1.07 & $0.73-1.56$ \\
\hline \multirow[t]{2}{*}{ University/higher } & 104 & 19.7 & 68 & 12.1 & 1.00 & \\
\hline & & & & & \multicolumn{2}{|c|}{$\chi^{2}=44.97, P<0.001$} \\
\hline Women & \multicolumn{2}{|c|}{$(n=940)$} & \multicolumn{2}{|c|}{$(n=14)$} & & \\
\hline Illiterate/read and write & 465 & 49.5 & 2 & 14.3 & 1.00 & \\
\hline Primary/preparatory & 147 & 15.6 & 2 & 14.3 & 3.16 & $0.44-22.65$ \\
\hline Secondary & 237 & 25.2 & 4 & 28.5 & 3.92 & $0.71-21.57$ \\
\hline \multirow[t]{2}{*}{ University/higher } & 91 & 9.7 & 6 & 42.9 & 15.33 & $3.05-77.14$ \\
\hline & & & & & \multicolumn{2}{|c|}{$\chi^{2}=13.21, P<0.001$} \\
\hline
\end{tabular}

Occupation $^{\mathrm{a}}$

Men

$$
(n=341) \quad(n=476)
$$

Professional/

semiprofessional

$\begin{array}{llll}68 & 19.9 & 62 & 13.1\end{array}$

Skilled/semiskilled

Manual

$57 \quad 16.7$

$54 \quad 11.3$

1.00

$\begin{array}{llll}162 & 47.5 & 265 & 55.7\end{array}$

1.04

1.79

$0.61-1.69$

Others $^{b}$

54

15.9

95

19.9

Women

Professional/

$(n=109)$

$(n=7)$

semiprofessional

Skilled/semiskilled

$53 \quad 48.6$

$\chi^{2}=12.26, P<0.001$

Manual

Others $^{b}$

$22 \quad 20.2$

$32 \quad 29.4$

21.8

$\begin{array}{cc}3 & 42.9 \\ 3 & 42.9 \\ 1 & 14.2 \\ 0 & 0\end{array}$
1.92
$0.19-19.26$
4.64
1.00

$$
\chi^{2}=0.11, P=0.74
$$

Marital status ${ }^{\mathrm{c}}$

\begin{tabular}{lrrrrrr} 
Men & \multicolumn{2}{c}{$(n=400)$} & \multicolumn{2}{c}{$(n=530)$} \\
Single $^{\mathrm{d}}$ & 125 & 31.2 & 110 & 20.8 & 1.00 & \\
Married & 275 & 68.8 & 420 & 79.2 & 1.74 & $1.27-2.36$
\end{tabular}




\begin{tabular}{|c|c|c|c|c|c|c|c|}
\hline \multicolumn{7}{|c|}{ Eastern Mediterranean Health Journal, Vol. 9, Nos 5/6, 2003} & \multirow[t]{2}{*}{927} \\
\hline Table 1 Demogr & racteris & of par & icipants & y smokir & tatus & (uded) & \\
\hline \multirow{2}{*}{$\begin{array}{l}\text { Demographic } \\
\text { characteristics }\end{array}$} & \multicolumn{2}{|c|}{ Never smokers } & \multicolumn{2}{|c|}{ Current smokers } & \multirow[t]{2}{*}{ OR } & \multirow[t]{2}{*}{$95 \% \mathrm{Cl}$} & \\
\hline & No. & $\%$ & No. & $\%$ & & & \\
\hline Women & \multicolumn{2}{|c|}{$(n=799)$} & \multicolumn{2}{|c|}{$(n=13)$} & & & \\
\hline Single ${ }^{d}$ & 151 & 18.9 & 3 & 23.1 & 1.00 & & \\
\hline Married & 648 & 81.1 & 10 & 76.9 & 0.78 & $0.19-3.60$ & \\
\hline
\end{tabular}

$\mathrm{n}=$ total number of respondents.

aApplicable only to those who were employed at the time of the survey.

${ }^{b}$ Others include drivers, traders and fishermen.

${ }^{c}$ Not applicable to students and those below the age of 18 years.

${ }^{d}$ Single includes never married, divorced, separated and widowed.

$\chi^{2}=$ chi-squared for linear trend.

1.07). The trend of greater tobacco use with lower educational level was significant statistically $(P<0.001)$. The trend was reversed among women $(P<0.001)$, as nearly half the women who were current smokers held a university degree (42.9\%). Relative to women who were illiterate or just able to read and write, a 3- to 4-fold increase in the risk of current tobacco use was observed among women who accomplished their basic or high school education whereas it was 15 times higher among those holding a university degree.

Considering those who were employed at the time of the survey, a significant linear association was observed between tobacco use and occupational categories among men $(P<0.001)$ (Table 1). Drivers, traders and fisherman were 1.93 times more likely to be current tobacco users than were professionals and semi-professionals, whereas the risk was 1.79 times among manual labourers and decreased to 1.04 among skilled and semi-skilled workers. On the other hand, no statistically significant difference was observed among women in relation to different occupational categories $(P=0.74)$.

Among men, a significantly higher percentage of current smokers $(79.2 \%)$ were married than never smokers (68.8\%). Mar- ried men were 1.74 times more likely to be tobacco users than single men. Among women, those who were married were less likely to be tobacco users than were single women yet this difference was not statistically significant (Table 1).

Significantly more chronic health problems were reported among men who were current smokers (9.6\%) than never smokers (5.9\%) (Table 2). Indeed, current smokers were 1.70 times more likely to suffer chronic health problems than never smokers. For women, more current smokers $(21.4 \%)$ reported chronic health problems than did never smokers (6.6\%), but this was not significant statistically. Adjusted for sex, current smokers were 1.81 times more likely to endure chronic health problems than never smokers. As regards physical activity, slightly more current smokers reported leading a sedentary life or performing light activity compared with never smokers among men $(92.7 \%$ versus $90.1 \%)$ and women (100.0\% versus $97.3 \%)$; however, the differences were not significant.

Table 3 shows the proportion of participants who were able to recognize the health problems associated with tobacco use without being prompted. Nearly equal percentages of current smokers and never

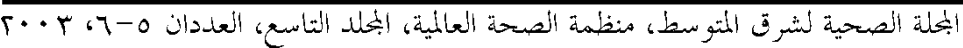


smokers knew that tobacco use is associated with a risk of chronic bronchitis and lung cancer among both active and passive smokers and is associated with atherosclerosis, heart diseases and cerebrovascular stroke. On the other hand, significantly more never smokers than current smokers knew that tobacco use is associated with a wide range of carcinomas, namely carcinoma of the larynx, oral cavity, urinary bladder and the female genital system as well as premature death. In addition, significantly more never smokers knew that tobacco use among women is associated with infertility as well as abortion, intrauterine fetal death and low birth weight. On the knowledge scale, the mean score of never smokers $(25.77 \pm 8.38$, range $14-42)$ was significantly higher than that of current smokers (24.96 \pm 6.97 , range $14-42)(P=$ 0.04).

The great majority of current smokers (94.3\%) knew that they were endangering the health of others who are exposed to tobacco smoke. Similarly, the majority of never smokers $(90.3 \%)$ recognized that their health was affected by being exposed to environmental tobacco smoke.

The mass media was the source of knowledge about the health effects of tobacco use for the majority of current smokers (89.7\%) and never smokers (93.7\%). On the other hand, few of the current smokers $(6.8 \%)$ and never smokers (3.6\%) obtained their knowledge from medical personnel, whereas family mem-

\begin{tabular}{|c|c|c|c|c|c|c|}
\hline \multirow{2}{*}{$\begin{array}{l}\text { Health problemsl } \\
\text { activities reported }\end{array}$} & \multicolumn{2}{|c|}{ Never smokers } & \multicolumn{2}{|c|}{ Current smokers } & \multirow[t]{2}{*}{ OR } & \multirow[t]{2}{*}{$95 \% \mathrm{Cl}$} \\
\hline & No. & $\%$ & No. & $\%$ & & \\
\hline \multicolumn{7}{|l|}{ Chronic health problems } \\
\hline Men & \multicolumn{2}{|c|}{$(n=529)$} & \multicolumn{2}{|c|}{$(n=563)$} & & \\
\hline Yes & 31 & 5.9 & 54 & 9.6 & 1.70 & $1.05-2.77$ \\
\hline No & 498 & 94.1 & 509 & 90.4 & 1.00 & \\
\hline Women & \multicolumn{2}{|c|}{$(n=940)$} & \multicolumn{2}{|c|}{$(n=14)$} & & \\
\hline Yes & 62 & 6.6 & 3 & 21.4 & 3.87 & $0.83-15.47$ \\
\hline No & 878 & 93.4 & 11 & 78.6 & 1.00 & \\
\hline Sex-adjusted values & & & & & 1.81 & $1.15-2.94$ \\
\hline \multicolumn{7}{|l|}{ Physical activity } \\
\hline Men & \multicolumn{2}{|c|}{$(n=529)$} & \multicolumn{2}{|c|}{$(n=563)$} & & \\
\hline Sedentary/light & 477 & 90.1 & 522 & 92.7 & 1.39 & $0.89-2.18$ \\
\hline Moderate/vigorous & 52 & 9.9 & 41 & 7.3 & 1.00 & \\
\hline Women & \multicolumn{2}{|c|}{$(n=940)$} & \multicolumn{2}{|c|}{$(n=14)$} & & \\
\hline Sedentary/light & 915 & 97.3 & 14 & 100.0 & 0.38 & $0.05-8.09$ \\
\hline Moderate/vigorous ${ }^{a}$ & 25 & 2.7 & 0 & 0 & 1.00 & \\
\hline Sex-adjusted values & & & & & 1.34 & $0.86-2.10$ \\
\hline
\end{tabular}

$\mathrm{n}=$ total number of respondents.

${ }^{a}$ An arbitrary 1 was added to the empty cell for the calculation of OR. 
bers and acquaintances were the source of knowledge for the remaining proportion.

Never smokers had significantly higher mean scores than current smokers on the scales measuring their perceptions of the danger associated with tobacco use $(P<$ $0.001)$, the susceptibility of tobacco users to tobacco-related illnesses $(P<0.001)$ and the benefits associated with not starting or giving up tobacco use $(P<0.001)$ (Table 4).

Tobacco use was modelled as a function of participants' characteristics as well as their knowledge and perceptions (Table 5). The characteristics included were: age, sex, education, marital status, existing health problems and level of physical activity (occupation was excluded from the model as it is related to educational attainment and it would have reduced the number of participants). The model revealed that the independent predictors of continuous use of tobacco were: male sex, older age, illiteracy, low perceptions of the benefits of staying tobacco-free and low perceptions of the susceptibility of tobacco users to health-related illnesses. This model correctly classified $82.8 \%$ of the participants.

\begin{tabular}{|c|c|c|c|c|c|c|}
\hline \multirow{2}{*}{$\begin{array}{l}\text { Health effects } \\
\text { recognized without } \\
\text { prompting }\end{array}$} & \multicolumn{2}{|c|}{$\begin{array}{c}\text { Never smokers } \\
(n=1469)\end{array}$} & \multicolumn{2}{|c|}{$\begin{array}{l}\text { Current smokers } \\
\quad(n=577)\end{array}$} & \multirow[t]{2}{*}{$\chi_{1}^{2}$-value } & \multirow[t]{2}{*}{$P$-value } \\
\hline & No. & $\%$ & No. & $\%$ & & \\
\hline Chronic bronchitis & 1049 & 71.4 & 408 & 70.7 & 1.00 & 0.754 \\
\hline Lung cancer & 849 & 57.8 & 308 & 53.4 & 3.29 & 0.070 \\
\hline $\begin{array}{l}\text { Chronic bronchitis in } \\
\text { passive smokers }\end{array}$ & 773 & 52.6 & 304 & 52.7 & 0.00 & 0.979 \\
\hline Heart disease & 778 & 53.0 & 285 & 49.4 & 2.11 & 0.146 \\
\hline Atherosclerosis & 711 & 48.4 & 255 & 44.2 & 2.94 & 0.086 \\
\hline $\begin{array}{l}\text { Lung cancer in passive } \\
\text { smokers }\end{array}$ & 615 & 41.9 & 223 & 38.6 & 1.77 & 0.183 \\
\hline Laryngeal cancer & 536 & 36.5 & 176 & 30.5 & 6.54 & 0.011 \\
\hline Cerebral stroke & 381 & 25.9 & 151 & 26.2 & 0.01 & 0.914 \\
\hline Cancer of oral cavity & 342 & 23.3 & 98 & 17.0 & 9.73 & 0.002 \\
\hline Bladder cancer & 335 & 22.8 & 95 & 16.5 & 10.03 & 0.002 \\
\hline $\begin{array}{l}\text { Cancer of female genital } \\
\text { tract }\end{array}$ & 291 & 19.8 & 78 & 13.5 & 11.09 & 0.001 \\
\hline Infertility in women & 267 & 18.2 & 71 & 12.3 & 10.35 & 0.001 \\
\hline Premature death & 232 & 15.8 & 67 & 11.6 & 5.80 & 0.016 \\
\hline $\begin{array}{l}\text { Abortion, intrauterine fet } \\
\text { death and low birth } \\
\text { weight }\end{array}$ & 220 & 15.0 & 56 & 9.7 & 9.86 & 0.002 \\
\hline
\end{tabular}

$\mathrm{n}=$ total number of respondents.

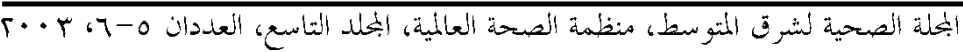




\begin{tabular}{|c|c|c|c|c|c|c|}
\hline \multirow[t]{2}{*}{ Risks perceived } & \multicolumn{2}{|c|}{ Never smokers $(n=1469)$} & \multicolumn{2}{|c|}{ Current smokers $(n=577)$} & \multirow[t]{2}{*}{$t$-value } & \multirow[t]{2}{*}{$P$-value } \\
\hline & $\begin{array}{c}\text { Mean score } \\
\pm s\end{array}$ & $95 \% \mathrm{Cl}$ & $\begin{array}{c}\text { Mean score } \\
\pm s\end{array}$ & $95 \% \mathrm{Cl}$ & & \\
\hline $\begin{array}{c}\text { Dangers of } \\
\text { smoking }\end{array}$ & $12.84 \pm 2.14$ & $12.74-12.95$ & $9.64 \pm 3.45$ & $9.36-9.93$ & 25.29 & $<0.001$ \\
\hline $\begin{array}{l}\text { Susceptibility } \\
\text { to illness }\end{array}$ & $9.14 \pm 1.64$ & $9.06-9.22$ & $6.85 \pm 2.38$ & $6.66-7.05$ & 25.94 & $<0.001$ \\
\hline $\begin{array}{l}\text { Benefits of not } \\
\text { smoking }\end{array}$ & $12.85 \pm 1.93$ & $12.73-12.96$ & $9.54 \pm 3.41$ & $9.26-9.82$ & 24.73 & $<0.001$ \\
\hline
\end{tabular}

$\mathrm{s}=$ standard deviation

\section{Discussion}

Tobacco surveys are important tools for identifying key issues and target groups, monitoring progress over time and placing tobacco control on the public agenda [9]. The prevalence of smoking from this sur- vey has already been reported in more detail [8]; nearly half of the men (48.5\%) were current smokers compared with only $1.5 \%$ of women. The current rate is suggestive of an increasing trend of smoking prevalence among men [3].

\begin{tabular}{|c|c|c|c|c|c|}
\hline Independent predictor & Coefficient & SE & Adjusted OR & $95 \% \mathrm{Cl}$ & $P$-value \\
\hline \multicolumn{6}{|l|}{ Age (years) } \\
\hline \multicolumn{6}{|l|}{$15-24^{a}$} \\
\hline $25-34$ & 0.5840 & 0.1978 & 1.79 & $1.22-2.64$ & 0.003 \\
\hline $35-44$ & 1.0216 & 0.2034 & 2.78 & $1.86-4.14$ & $<0.001$ \\
\hline $45-54$ & 1.1818 & 0.2107 & 3.26 & $2.16-4.93$ & $<0.001$ \\
\hline $55+$ & 0.7197 & 0.2428 & 2.05 & $1.28-3.31$ & 0.003 \\
\hline \multicolumn{6}{|l|}{ Sex } \\
\hline \multicolumn{6}{|l|}{ Women ${ }^{\mathrm{a}}$} \\
\hline Men & 4.0309 & 0.2839 & 56.31 & 32.28-98.24 & $<0.001$ \\
\hline \multicolumn{6}{|l|}{ Education } \\
\hline \multicolumn{6}{|l|}{ University/highera } \\
\hline Illiterate/read and write & 0.4311 & 0.2024 & 1.54 & $1.03-2.28$ & 0.033 \\
\hline Primary/preparatory & 0.0006 & 0.2488 & 1.00 & $0.61-1.63$ & 0.998 \\
\hline Secondary & 0.0673 & 0.2142 & 1.06 & $0.70-1.63$ & 0.753 \\
\hline \multicolumn{6}{|l|}{ Perception scales } \\
\hline Perception of benefits & -0.1743 & 0.0537 & 0.84 & $0.75-0.93$ & 0.001 \\
\hline Perception of susceptibility & -0.1501 & 0.0744 & 0.86 & $0.74-0.99$ & 0.044 \\
\hline
\end{tabular}

${ }^{a}$ Reference category.

$S E=$ standard error.

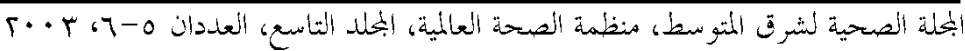


This study as well as others [10-12] has shown higher tobacco use among men who are currently married. Tobacco use by parents or future parents increases the risk of smoking among children as their attitudes towards smoking are influenced by their parents' behaviour [13-15]. More importantly, exposure to smoking is a hazard to all household inhabitants as it increases the risk of acute respiratory diseases and asthma among children $[1,16,17]$ as well as lung cancer, late asthma and ischaemic heart diseases among adults $[18,19]$.

Social class, measured by participants' educational attainment and occupational category, significantly predicted current tobacco use. Among men, the risk of current tobacco use increased progressively with decreasing occupational rank and educational attainment. Eisner et al. pointed to educational attainment as the most potent predictor of smoking among the general population [20]. Similar associations between educational attainment and smoking prevalence were reported from Europe [21,22], the USA [16] and Mauritius [23] while a reversed association was reported from Saudi Arabia [10,11]. It has been observed that when antismoking campaigns take effect, prevalence rates tend to fall among the better educated, resulting in a higher prevalence among the lower socioeconomic groups, with a widening gap over time [7]. The fact that tobacco use by women is mostly among the highly educated matches with the evolution of tobacco use in industrialized societies. At the beginning of the epidemic, when the overall prevalence among women was low, as in the present case, the habit was first adopted by the more affluent and educated, usually in large cities [13].

The fact that tobacco use starts during adolescence is undisputed [13,24], yet our findings provide substantial evidence that increasing current age of participants inde- pendently predicts continuing use. It is likely that after many years of smoking, users become strongly dependent on their drug [9]. Also, many long-term smokers may lack the motive to quit because they may believe that they are no longer susceptible to the risk of tobacco-related disease after surviving smoking for many years, whereas others may believe that any damage that may have accrued is irreversible [17]. In this study, more current tobacco users than never smokers reported chronic ailments that may have been caused by smoking. However, those who are disease-free can still benefit by giving up the habit as the benefits of cessation extend to quitting even at older ages [17].

Surveys of public knowledge about tobacco use and the associated health hazards are essential for revealing gaps in knowledge and are important tools for the planning and evaluation of educational campaigns. In this respect, both prompted awareness and unprompted knowledge were verified. Prompted responses that reflect recognition may be useful for testing the impact of new education or communication campaigns whereas unprompted responses reflect knowledge that is more likely to influence behaviour [9]. Previous knowledge surveys $[13,25,26]$ have demonstrated that users of tobacco products are less knowledgeable about the health risks of smoking than those who remain tobacco-free and our survey is no exception to these findings. Both current smokers and never smokers recognized the risk of cardiovascular and cerebrovascular accidents as well as respiratory illnesses. This is expected, as these are the major health issues commonly addressed by antismoking educational activities. In contrast, current smokers were much less aware that the adverse effects of tobacco use extend to malignancy in other organs, prema-

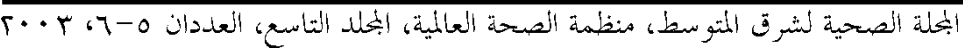


ture death, infertility and poor pregnancy outcomes. This lack of awareness could be attributed to a denial mechanism, as cancer and premature death are highly feared. Unfortunately, smokers also tend to attribute positive qualities to smoking, including attractiveness, a masculine appearance and sophistication [26], and refuse to admit the danger it carries $[25,26]$. The hazards of tobacco use, susceptibility of users and the benefits of being tobacco-free were poorly perceived by current smokers in the present survey. Indeed, it was individuals' perceptions, rather than their knowledge, that independently predicted continuing tobacco use. This is not surprising, as beliefs are a more lasting and more powerful influence on behaviour than merely having knowledge. However, most theories of behaviour assume that knowledge is necessary for shaping an individual's perceptions and attitudes.

It is evident that public education is an important component of anti-smoking campaigns. Health education messages should emphasize the fact that smoking represents the most extensively documented cause of disease ever investigated in the history of biomedical research [17]. The health risks of tobacco use may even be underestimated due to the 30 to 40 year lag between initiation and the death that may result $[7,16]$. The mass media was the source of relevant knowledge about smoking for about $90 \%$ of the interviewed population. Health education messages should definitely consider the cultural background, characteristics of the target groups and level of literacy. It is likely that health messages, which are largely cognitive in nature, mainly affect the behaviour of the highly educated sector of the population [21]. A major priority for public health is the development of health education messages tailored to the lower socioeconomic groups, stressing equally the seriousness of the habit and the benefits of remaining tobacco-free.

Despite the low prevalence of smoking among women in our study, women's education should not be overlooked, as their smoking patterns usually mirror those of men after many years' delay. This is particularly likely in view of weakened cultural norms, better education and higher career achievement among women, with subsequent increases in women's spending power. If this occurs, it will undo much of the progress made in health and development of women in developing parts of the world including Egypt [13].

There are sound economic reasons for improving health education about smoking in Egypt. Tobacco use results in a global net cost of US\$200 billion per year, half of this in developing countries. Meanwhile, in developing countries with a per capita gross production of US\$2000, smoking prevention costs approximately US\$ 20-40 per year of life gained. On the other hand, lung cancer treatment, which can prolong the lives of only about $10 \%$ of the affected people, costs US\$ 18000 per year of life gained [5]. Thus, prevention is among the most cost-effective of all health interventions against smoking-related diseases.

\section{Acknowledgement}

The authors acknowledge the World Health Organization Regional Office for the Eastern Mediterranean for funding this research. 


\section{References}

1. Sports and the arts without tobacco play it tobacco free. Tobacco alert: 1996 World No-Tobacco Day advisory kit. Geneva, World Health Organization, 1996.

2. Tobacco or health: a global status report. Geneva, World Health Organization, 1997.

3. Omar $\mathrm{S}$ et al. Prevention of tobacco epidemic in a developing country - Egypt. A review article. Armed forces journal, 1984, 28(2):136-46.

4. Gomma RA. Report of health interview survey. Health profile of Egypt: results of the first cycle. Publication no. 16. Cairo, Ministry of Health and Population, 1982.

5. Office of Health Communications and Public Relations. Tobacco epidemic: much more than a health issue: tobacco use is a major drain on the world's financial resources. WHO fact sheet, no. 155. Geneva, World Health Organization, 1998.

6. Baris $\mathrm{E}$ et al. Research priorities for tobacco control in developing countries: a regional approach to a global consultative process. Tobacco control, 2000, 9: 217-23.

7. Guidelines for controlling and monitoring the tobacco epidemic. Geneva, World Health Organization, 1998.

8. Youssef RM, Abou-Khatwa SA, Fouad HM. Prevalence of smoking and age of initiation in Alexandria, Egypt. Eastern Mediterranean health journal, 2002, 8(4/ 5):626-37.

9. Strengthening tobacco control in Central and Eastern Europe: proceedings of a training seminar, Warsaw, Poland, 2025 October 1995. Geneva, World Health Organization, 1996.
10. Tobacco epidemic: health dimensions: tobacco is a greater cause of death and disability than any single disease. WHO fact sheet, no. 154. Geneva, World Health Organization, 1998.

11. Jarallah JS et al. Prevalence and determinants of smoking in three regions of Saudi Arabia. Tobacco control, 1999, 8:53-6.

12. Saeed AAW, Khoja TA, Khan SB. Smoking behavior and attitudes among adult Saudi nationals in Riyadh city, Saudi Arabia. Tobacco control, 1996, 5:215-9.

13. Haddock CK et al. Smoking prevalence and risk factors for smoking in a population of United States Air Force basic trainees. Tobacco control, 1998, 7:232-5.

14. Challet-Traquet CM. Women and tobacco. Geneva, World Health Organization, 1992.

15. Smedslund G, Ahn DK. Smoking initiation and cessation in Norway and the United States: a comparison of two crosssectional surveys. Journal of substance abuse, 1998, 10(4):397-410.

16. Moody PM et al. Factors associated with the initiation of smoking by Kuwaiti males. Journal of substance abuse, 1998, 10(4):375-84.

17. The Surgeon General's 1990 report on the health benefits of smoking cessation. Morbidity and mortality weekly report. Recommendations and reports, 1990, 39(RR12):2-10.

18. WHO Tobacco or Health Programme. Tobacco alert. Geneva, World Health Organization, 1993.

19. McGhee SM et al. Passive smoking at work: the short-term cost. Journal of epidemiology and community health, 2000, 54(9):673-6.

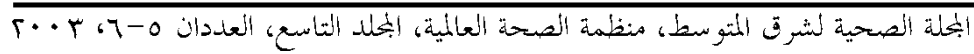


20. Eisner MD et al. Predictors of cigarette smoking and smoking cessation among adults with asthma. American journal of public health, 2000, 90(8):1307-11.

21. Cavelaars AEJM et al. Educational difference in smoking: international comparison. British medical journal, 2000, 320(7242):1102-7.

22. Setter $C$ et al. Impact of school and vocational education on smoking behaviour: results from a large-scale study on adolescents and young adults in Germany. Sozial- und praventivmedizin, 1998, 43(3):133-40.

23. Cox $\mathrm{HS}$ et al. Decreasing prevalence of cigarette smoking in the middle income country of Mauritius: questionnaire sur- vey. British medical journal, 2000, 321(7257):345-9.

24. Unger JB, Chen $X$. The role of social networks and media receptivity in predicting age of smoking initiation: a proportional hazards model of risk and protective factors. Addictive behaviors, 1999, 24(3):371-81.

25. Jarallah JS et al. Predictors of smoking among male junior secondary school students in Riyadh, Saudi Arabia. Tobacco control, 1996, 5:26-9.

26. Wiecha JM, Lee V, Hodgkins J. Patterns of smoking, risk factors for smoking, and smoking cessation among Vietnamese men in Massachusetts (United States). Tobacco control, 1998, 7:27-34.

\section{EMRO's Tobacco Free Initiative (TFI) website}

We would like to draw our readers' attention to the Tobacco Free Initiative (TFI) website of the WHO Regional Office for the Eastern Mediterranean. This site provides a wealth of information on TFI which is a WHO cabinet project created to focus international attention, resources and action on the global tobacco pandemic that kills nearly 5 million people a year. Included on the site is information on numerous aspects of TFI such as: the Framework Convention on Tobacco Control which is the flagship of WHO's efforts to control tobacco; Religion and tobacco; Legislation; TFI events; EMR country profiles; Press material; Key areas and groups; Tobacco industry's activities; and Partners involved in TFI. The site can be accessed free at: http://www.emro.who.int/tfi/tfi.htm 